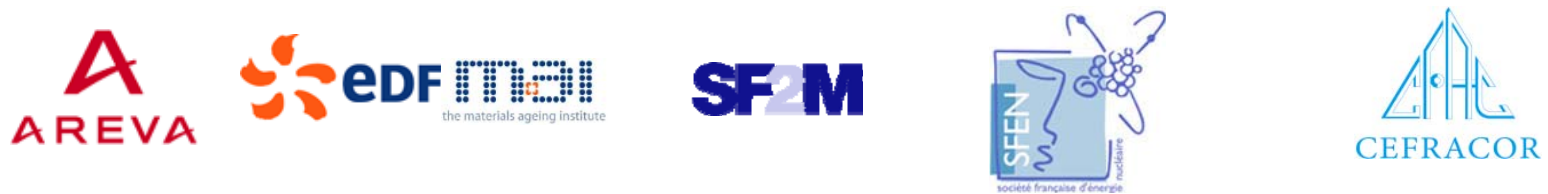

\section{MIN口S}

Centre of Excellence for Nuclear Materials

\section{Workshop}

Materials Innovation for Nuclear Optimized Systems
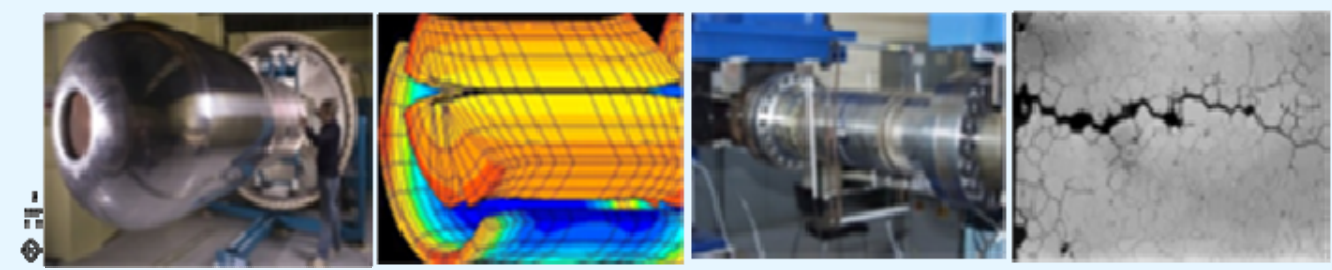

December 5-7, 2012, CEA - INSTN Saclay, France

\section{Pascal BELLON et al.}

University of Illinois (USA)

Phase and Microstructure Evolutions under Irradiation:

Design of Coarsening-Resistant Nanostructures

Workshop organized by:

Christophe GALLÉ, CEA/MINOS, Saclay - christophe.galle@cea.fr Constantin MEIS, CEA/INSTN, Saclay-constantin.meis@cea.fr 


\title{
Phase and Microstructure Evolutions under Irradiation: Design of Coarsening-resistant Nanostructures
}

\author{
Pascal BELLON ${ }^{1}$, Robert S. AVERBACK ${ }^{1}$ \\ ${ }^{1}$ Department of Materials Science and Engineering, University of Illinois at Urbana-Champaign (Urbana, IL, USA)
}

\begin{abstract}
Advanced nuclear energy systems will require materials that resist to very large doses of radiation damage. One strategy to accomplish that goal is to employ nanostructured materials, as their high density of sinks can dramatically enhance the trapping and the recombination of point defects, thus minimizing deleterious effects such as radiation-induced segregation and precipitation or swelling. A concern however is that these nanostructures would not be stable under irradiation and would undergo significant coarsening. We will discuss two possible approaches for designing coarsening resistant nanostructures.
\end{abstract}

The first approach relies on the spontaneous formation of nanostructures at steady-state under irradiation in immiscible alloys, when the chemical mixing forced by nuclear collisions compete with the decomposition promoted by thermally activated decomposition [1]. These nanostructures are thus, by design, stable under irradiation. Examples of such nanostructures are found in ion-irradiated $\mathrm{Cu}$ $\mathrm{Ag}, \mathrm{Cu}-\mathrm{Fe}$ and Cu-Co alloys [2], as seen in Fig. 1.

A second approach relies on the formation of nanoscale precipitates leading to a microstructure that is kinetically trapped, owing to very low solubility and diffusivity of the precipitating elements in the matrix. We successfully applied this approach by alloying $\mathrm{Cu}$ with refractory solute elements such as $\mathrm{Nb}$, Mo, and $\mathrm{W}$, and show that nanostructures in these systems can resist coarsening at temperatures up to $85 \%$ of the melting point of $\mathrm{Cu}$ [3], as illustrated in Fig. 2. We show that this approach offers rich possibilities by considering ternary alloy systems [4], and that, in addition to thermal annealing, irradiation or severe plastic deformation can be used to synthesize nanostructures optimized for coarsening resistance at high temperature or under irradiation. 


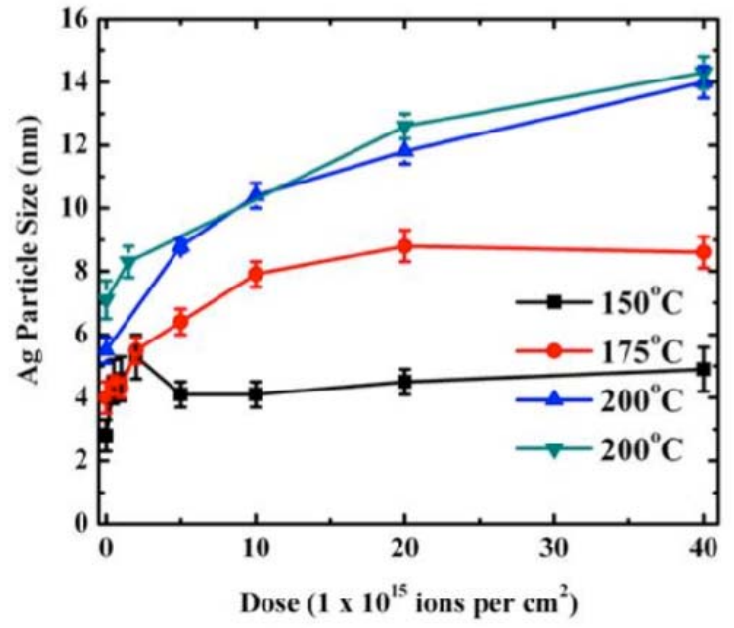

Fig. 1: Irradiation-induced nanopatterning in $\mathrm{Cu}_{90} \mathrm{Ag}_{10}$ thin film irradiated with $1.8 \mathrm{MeV}$ $\mathrm{Kr}$ ions at variable temperatures [2].

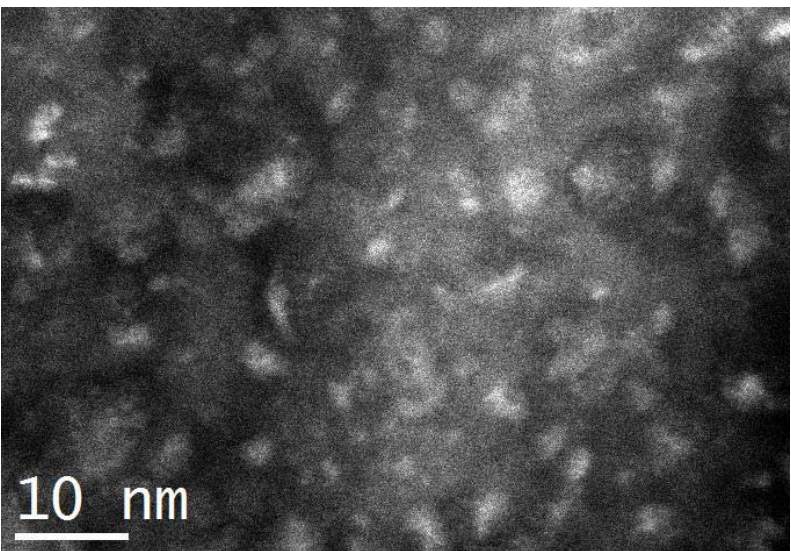

Fig. 2: Z-contrast TEM image of nanostructured $\mathrm{Cu}-\mathrm{Nb}-\mathrm{W}$ alloy with high resistance to thermal coarsening at $650^{\circ} \mathrm{C}$.

\section{References}

[1] R. Enrique, P. Bellon. Phys. Rev. Lett. 84, 2885 (2000).

[2] S. W. Chee, B. Stumphy, N. Q. Vo, R. S. Averback, P. Bellon. Acta. Mater. 58, 4088-4099 (2010).

[3] N. Q. Vo, S. W. Chee, D. Schwen, X. Zhang, P. Bellon, R. S. Averback. Scripta. Mater. 63, 929-932 (2010).

[4] X. Zhang, N. Q. Vo, P. Bellon, R. S. Averback. Acta. Mater. 59, 5332-5341 (2010). 


\section{Phase and microstructure evolutions under irradiation : Design of coarsening-resistant nanostructures}

Robert S. Averback, Shen Dillon, Pascal Bellon (UIUC)

Nhon Q. Vo* (NWU), Xuan Zhang (UIUC), Shimin Mao (UIUC)

\section{Outline}

1. Nanostructuration for radiation resistance

2. Design of coarsening-resistant nanostructures

3. Evaluation of sink efficiency under irradiation 


\section{Need for New Materials Resistant to Extreme Irradiation and Temperature Environments}

Materials problems

solute segregation, creep,

embrittlement, swelling

Conventional materials

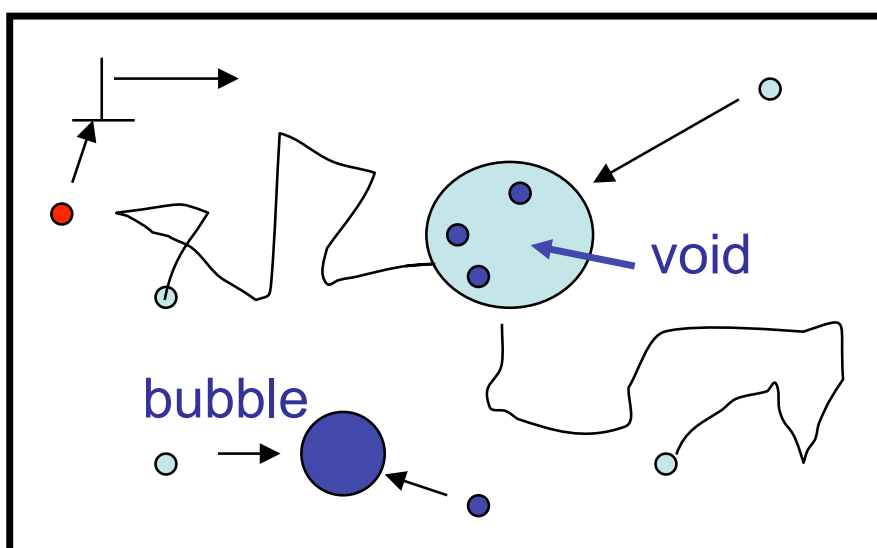

o vacancy o interstitial oHe atom
Next generation of nuclear reactors:

Need for materials that can last

50-100 years in extreme environments.

Nanostructured materials
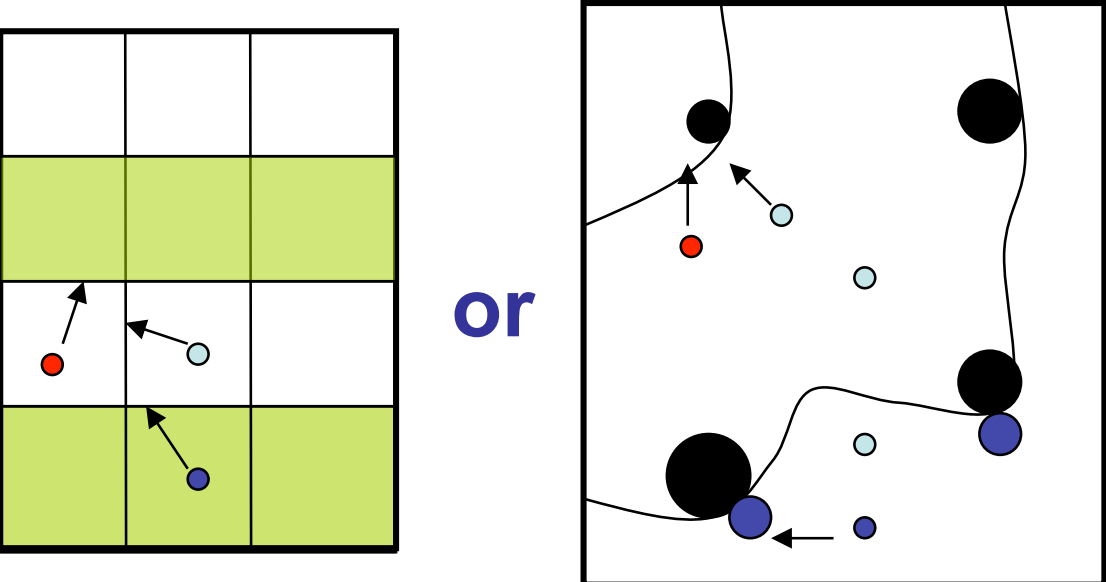

$\rightarrow$ How to stabilize nanostructures under irradiation?

$\rightarrow$ How to optimize their radiation resistance, e.g., sink efficiency?

$\Rightarrow$ How to tailor their mechanical properties? 


\section{Part I: Some approaches to suppress}

\section{coarsening of nanoprecipitates using ternary alloys}

1. Core/shell nanostructures with shell comprised of slow diffuser

e.g., $\mathrm{Al}_{3} \mathrm{Sc} / \mathrm{Al}_{3} \mathrm{Zr}$

$30 \mathrm{~nm}$

HAADF-TEM

Nature Materials, Clouet et al. 2006
2. Core/shell structures with slower diffuser in the core: "size-focusing regime"

e.g., $\mathrm{Al}_{3} \mathrm{Sc} / \mathrm{Al}_{3} \mathrm{Li}$

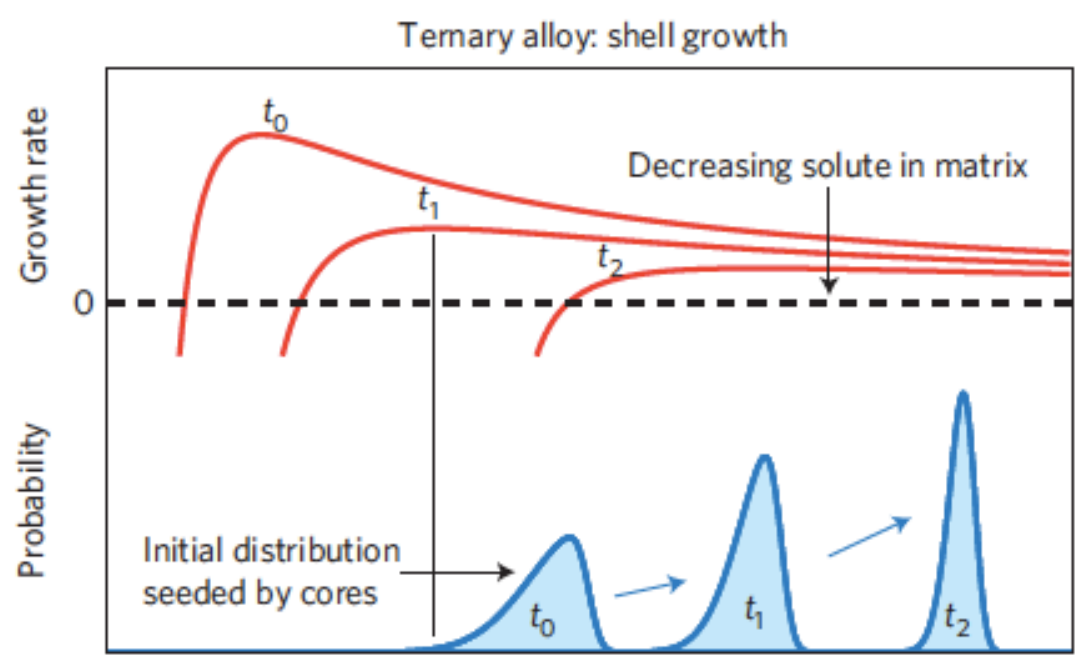

Precipitate radius

Nature Materials, Radmilovic et al. 2011

$\rightarrow$ Coarsening by cascade of local instability

$\rightarrow$ Coarsening suppressed but not stopped 


\section{Nanoscale patterning through self-organization in non-equilibrium alloy systems}

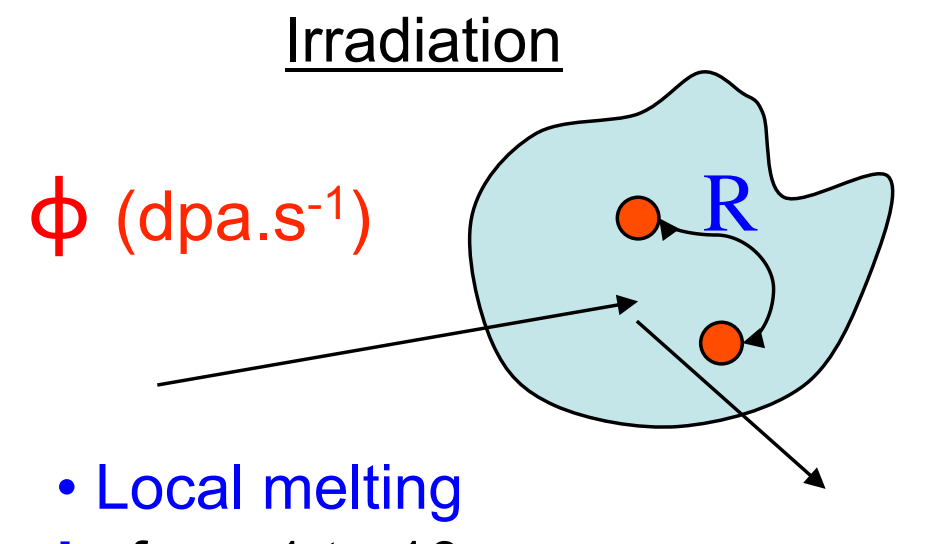

$\mathrm{L}$ : from 1 to $10 \mathrm{~nm}$ for $\mathrm{E}_{\mathrm{PKA}} \approx 10 \mathrm{keV}$ quasi-liquid for a few ps

- Ballistic mixing $\mathrm{R}$ : from $\approx 1$ to a few $\AA$ but medium range tail $(\mathrm{nm})$

- Spatially-biased defect production sustained defect/chemical fluxes leading to instabilities

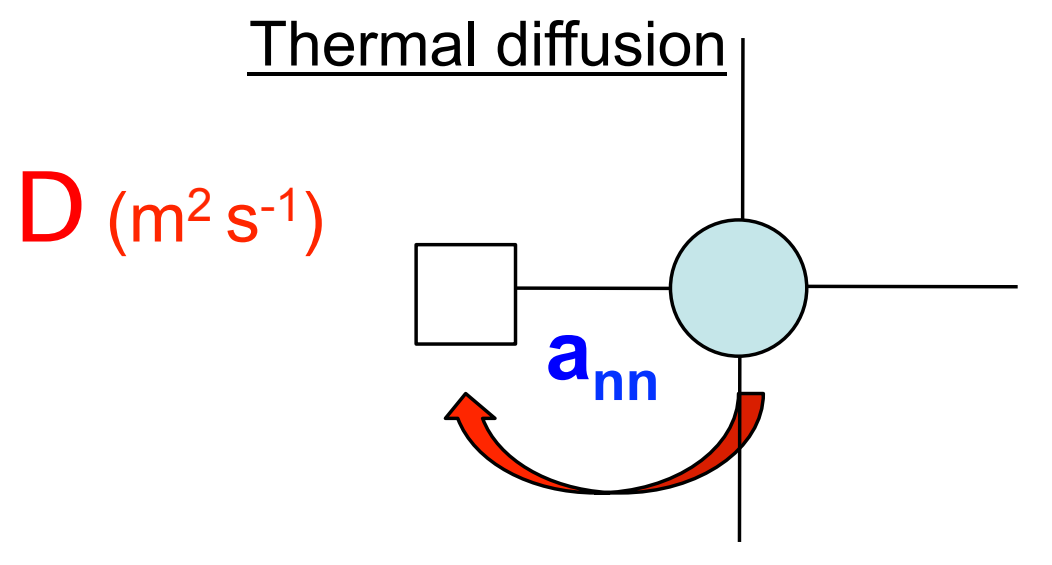

- Relaxation toward equilibrium

$\rightarrow$ Nanoscale patterning by:

1. Competition between processes

2. Intra-cascade precipitation

$\rightarrow$ Nanoprecipitate size stable by design

$\rightarrow$ Similar patterning in alloys subjected to severe plastic deformation 


\section{Nanoscale patterning in immiscible alloys under irradiation}

1. Moderately immiscible alloys: $\mathrm{Cu}_{90} \mathrm{Fe}_{10}$ $\rightarrow$ dynamical competition
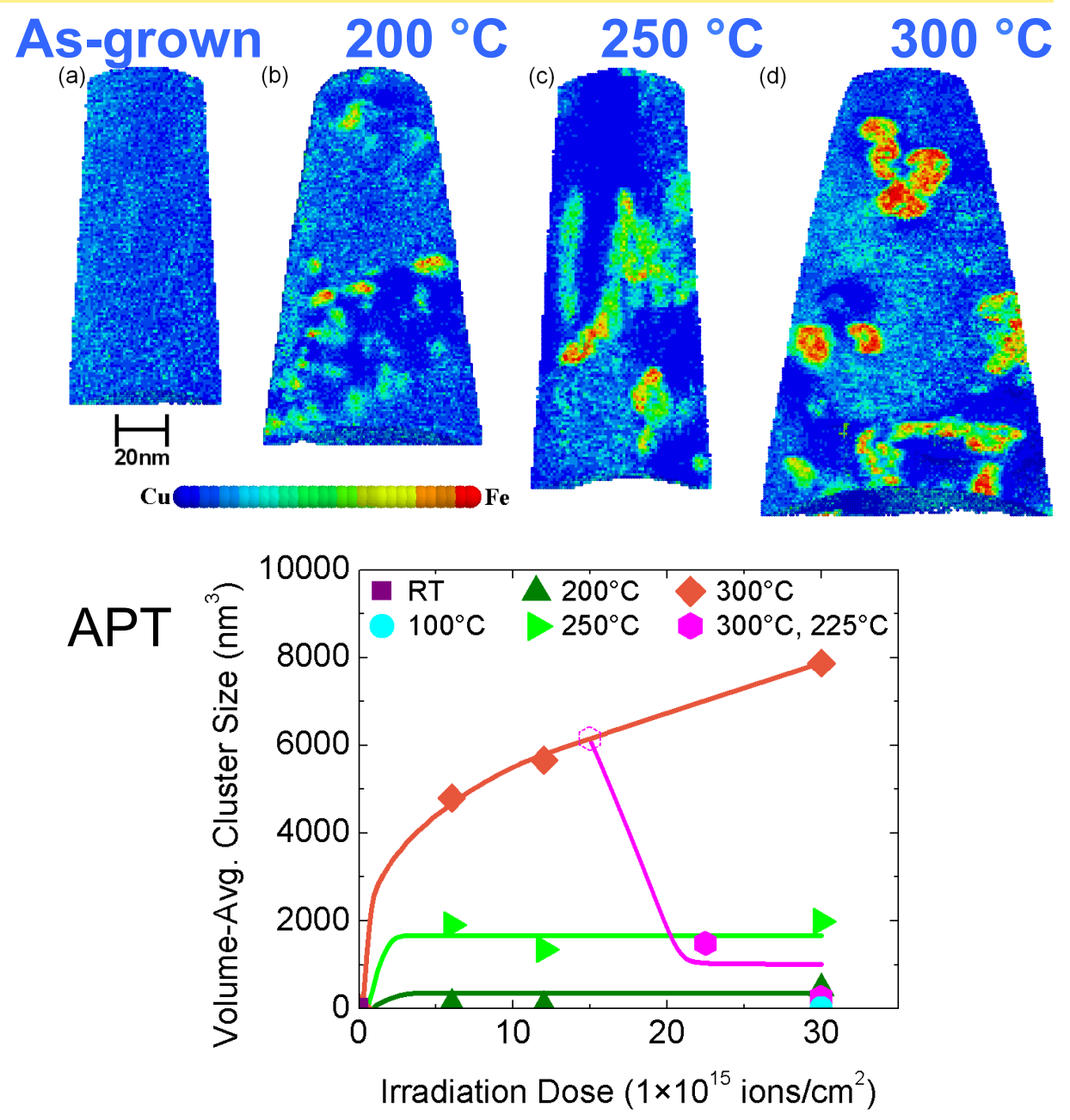

Chee et al. Acta Mater. 2010
2. Highly immiscible alloys: $\mathrm{Cu}_{90} \mathrm{Mo}_{10}$ $\rightarrow$ intracascade precipitation

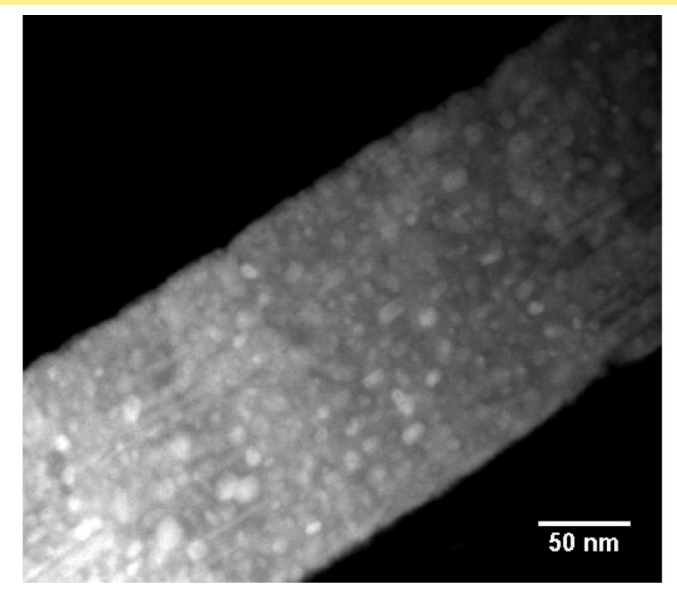

TEM

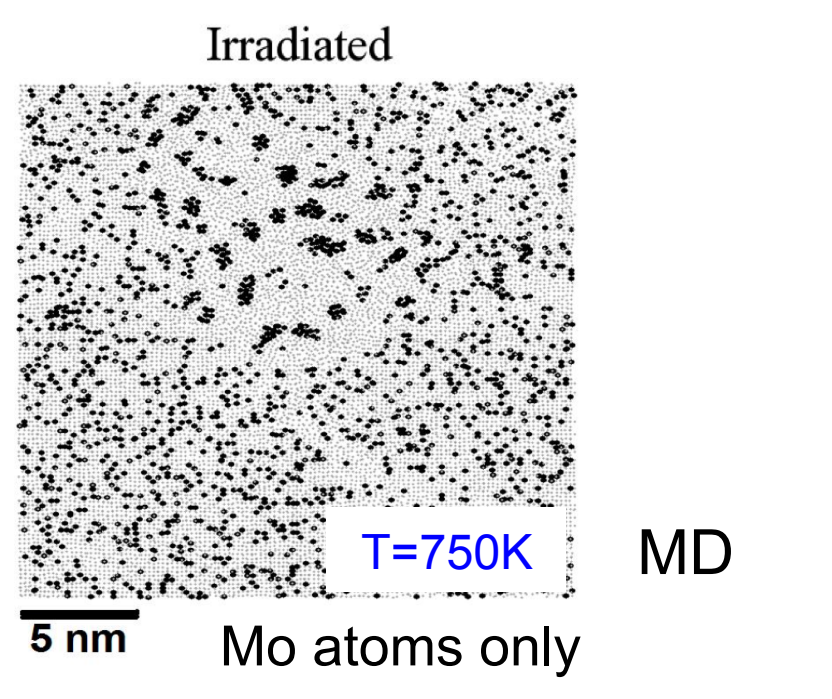

Vo et al. Scripta Mater. 2010 


\section{Cu-Nb-W: a model system for investigating patterning and coarsening at the nanoscale}

1. Cu-Nb immiscible in solid state only: patterning by dynamical competition Cu-W immiscible in the liquid state: patterning by intracascade precipitation

2. $\mathbf{N b}$ faster diffuser than $\mathbf{W}$ in $\mathbf{C u}$

$\rightarrow$ Competition between driving force and kinetics for precipitation

$\rightarrow$ Expect complex and frustrated nanostructures

Thin film of $\mathbf{C u}_{1-x-y} \mathbf{N b}_{x} \mathbf{W}_{y}$ grown by PVD at RT: solid solution
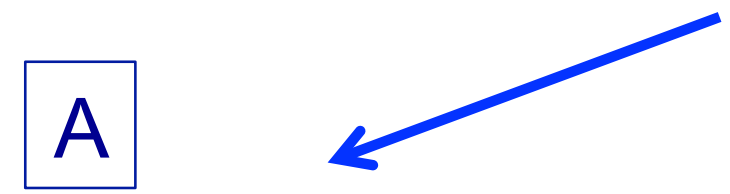

- Direct annealing or irradiation at elevated $\mathrm{T}, 650$ to $830{ }^{\circ} \mathrm{C}$

RBS, XRD, TEM, KMC

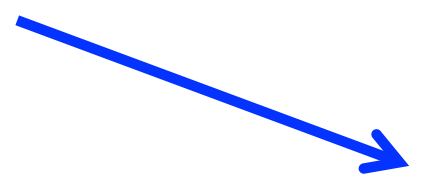

- RT 1.8 MeV irradiation up to $75 \mathrm{dpa}$

- Annealing or irradiation at elevated T, 650 to $830{ }^{\circ} \mathrm{C}$

RBS, XRD, TEM, KMC 


\section{A. Nanostructuring in $\mathrm{Cu}-\mathrm{Nb}-\mathrm{W}$ thin films: Precipitation in HT annealed samples (1)}

- $\mathrm{Cu}_{88.5} \mathrm{Nb}_{10} \mathrm{~W}_{1.5}$, annealed $1 \mathrm{hr}$ at $830^{\circ} \mathrm{C}$

- Experimental results:

- Nanoprecipitates at not too high T

- Small grains

- Apparent inverse coarsening in ternary alloy
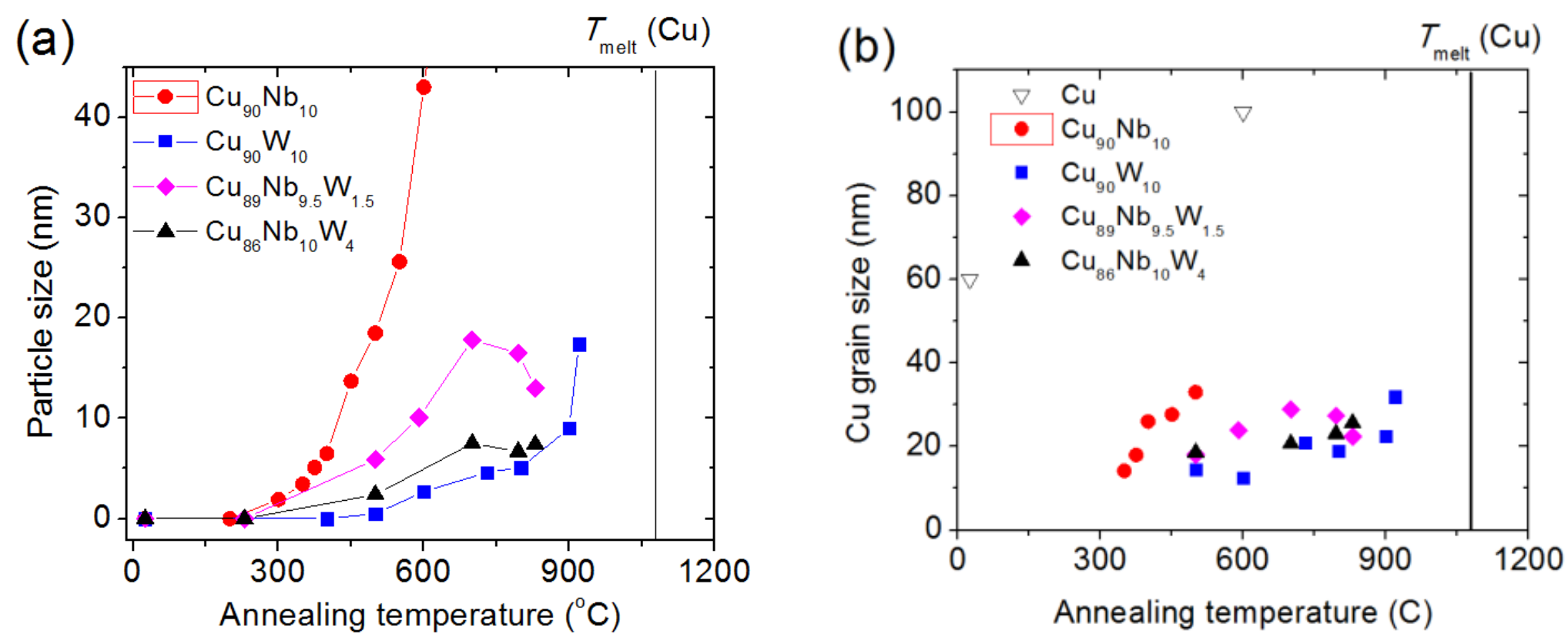


\section{A. Nanostructuring in $\mathrm{Cu}-\mathrm{Nb}-\mathrm{W}$ thin films: Precipitation in HT annealed samples (2)}

- $\mathrm{Cu}_{88.5} \mathrm{Nb}_{10} \mathrm{~W}_{1.5}$, annealed $1 \mathrm{hr}$ at $830^{\circ} \mathrm{C}$

- Experimental results:

- Bimodal precipitate size distribution;

- Smaller precipitates are richer in W;

- W-rich shell/Nb-rich core.

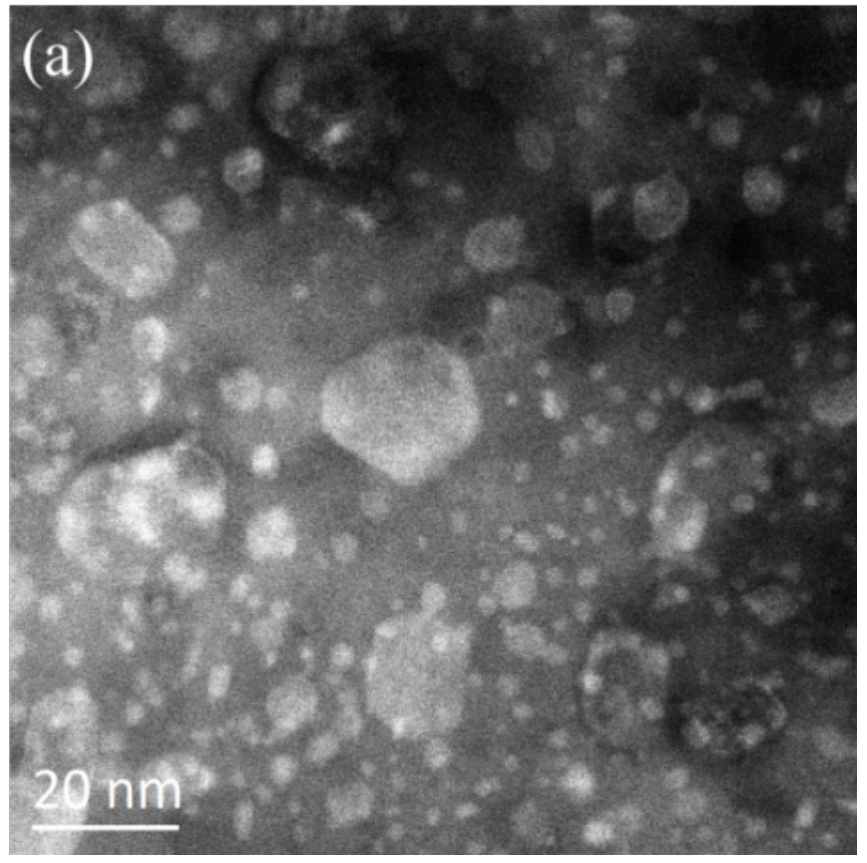

(b)
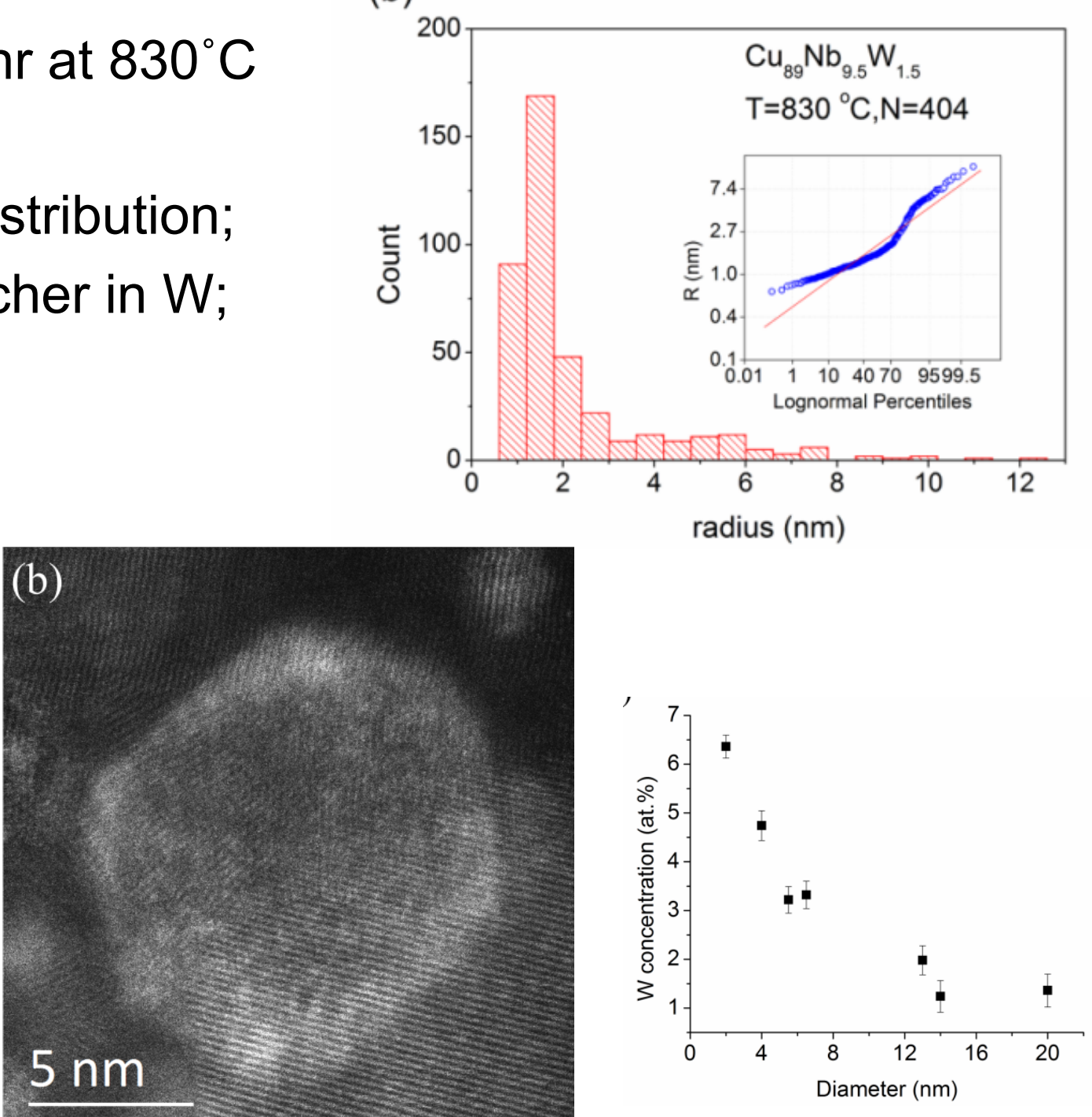


\section{B. Nanostructuring in $\mathrm{Cu}-\mathrm{Nb}-\mathrm{W}$ thin films: Precipitation in samples first irradiated at RT (1)}

$\mathrm{Cu}_{88.5} \mathrm{Nb}_{10} \mathrm{~W}_{1.5}$

- $\quad \mathrm{RT}$ pre-irradiation 1.8 MeV Kr (75 dpa), then $655^{\circ} \mathrm{C}$ annealing.

- RT irradiation: W precipitation;

- Annealing: Nb precipitation.

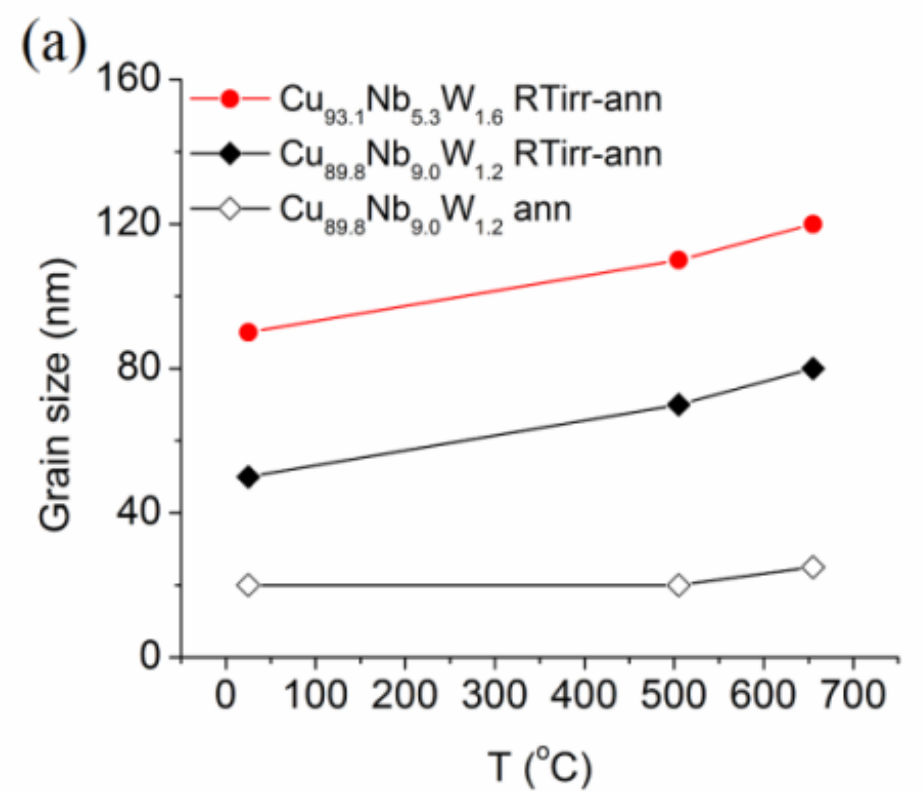

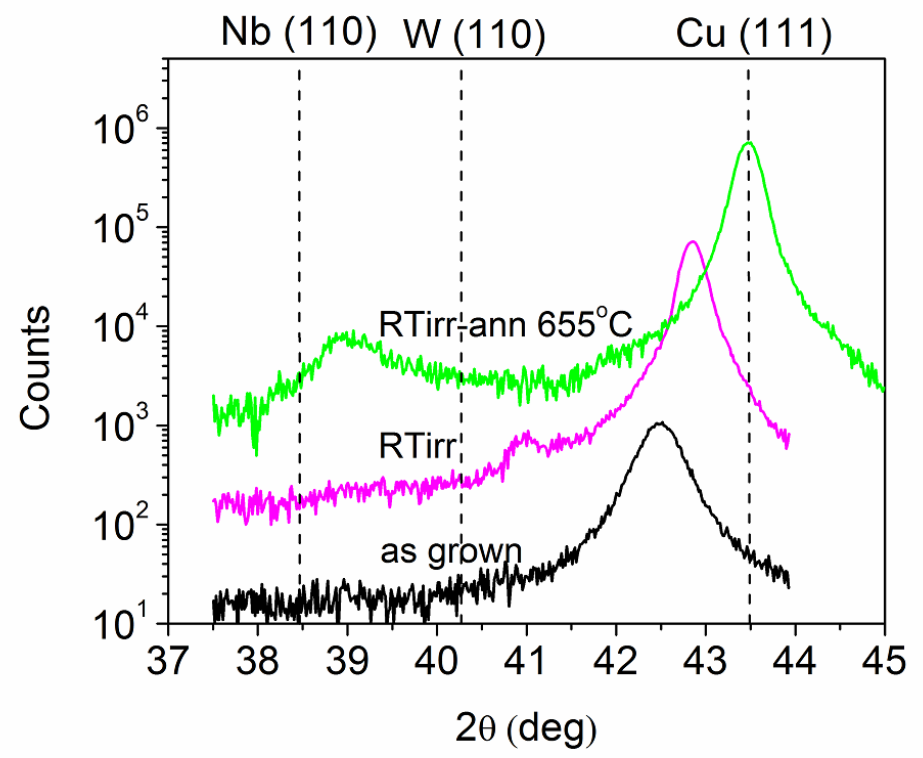

(b)

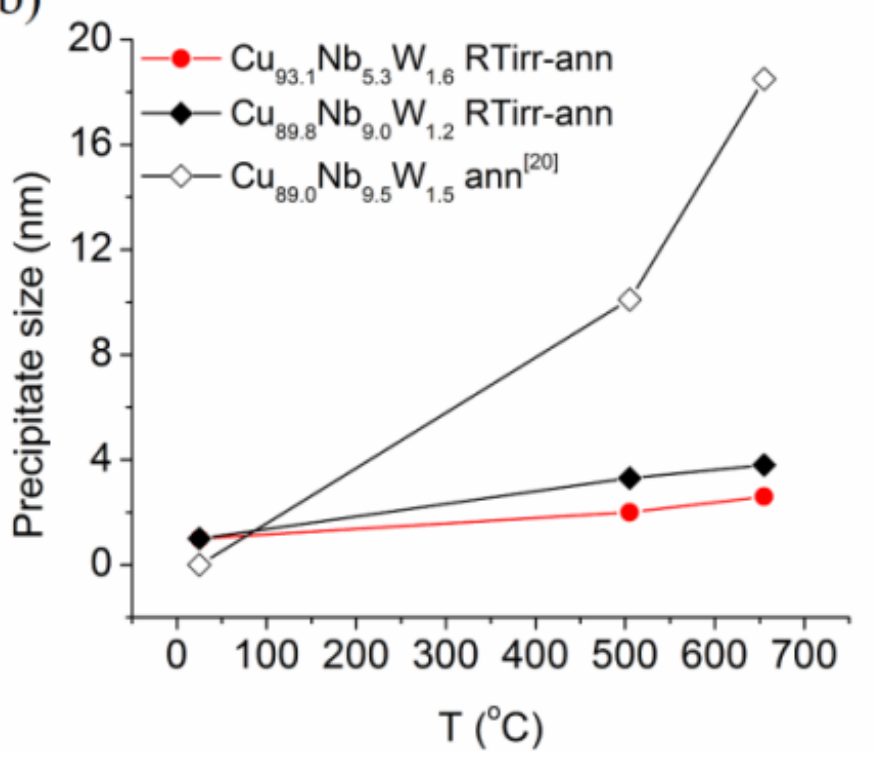

9 


\section{B. Nanostructuring in $\mathrm{Cu}-\mathrm{Nb}-\mathrm{W}$ thin films: Precipitation in samples first irradiated at RT (2)}

- Experimental results, cont'd:

- Ramified W precipitates after RT irradiation

- Uniform size distribution

- Moiré fringes: orientation relationship P/M (Bain)

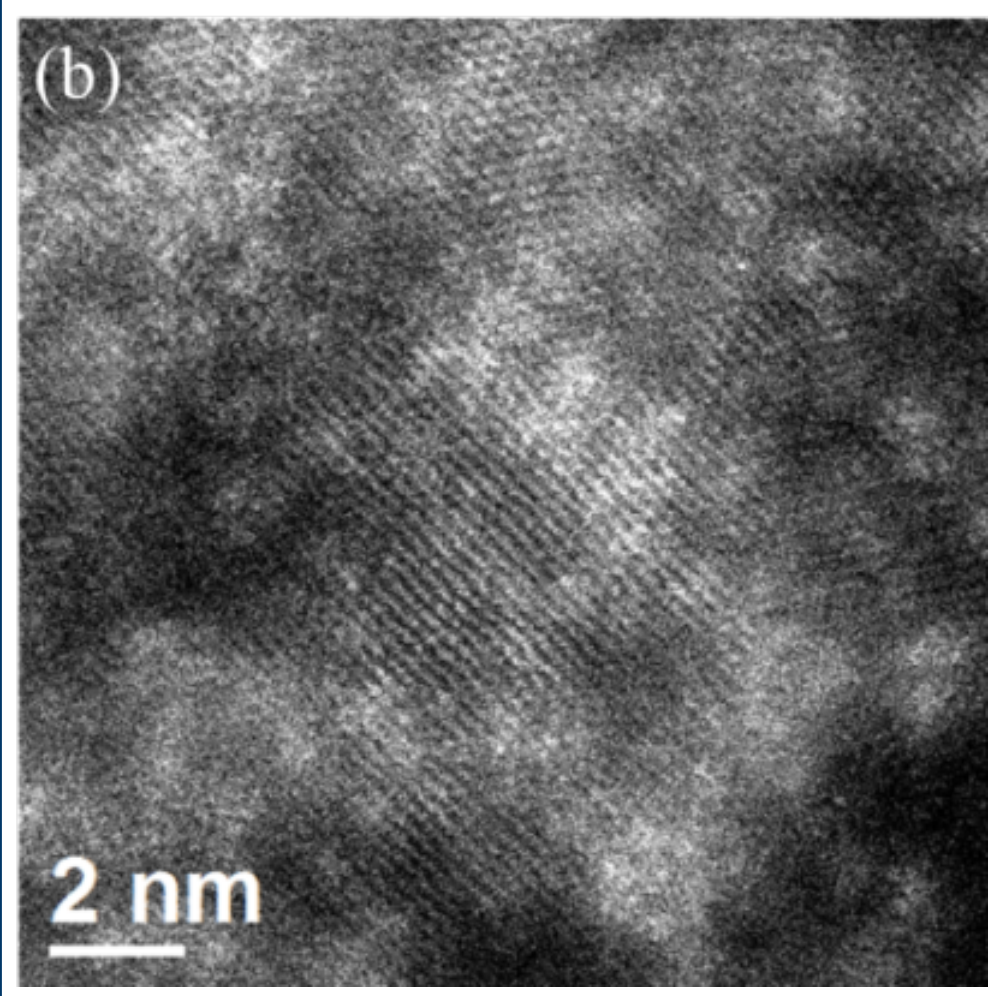

HAADF-TEM

\section{Annealing}

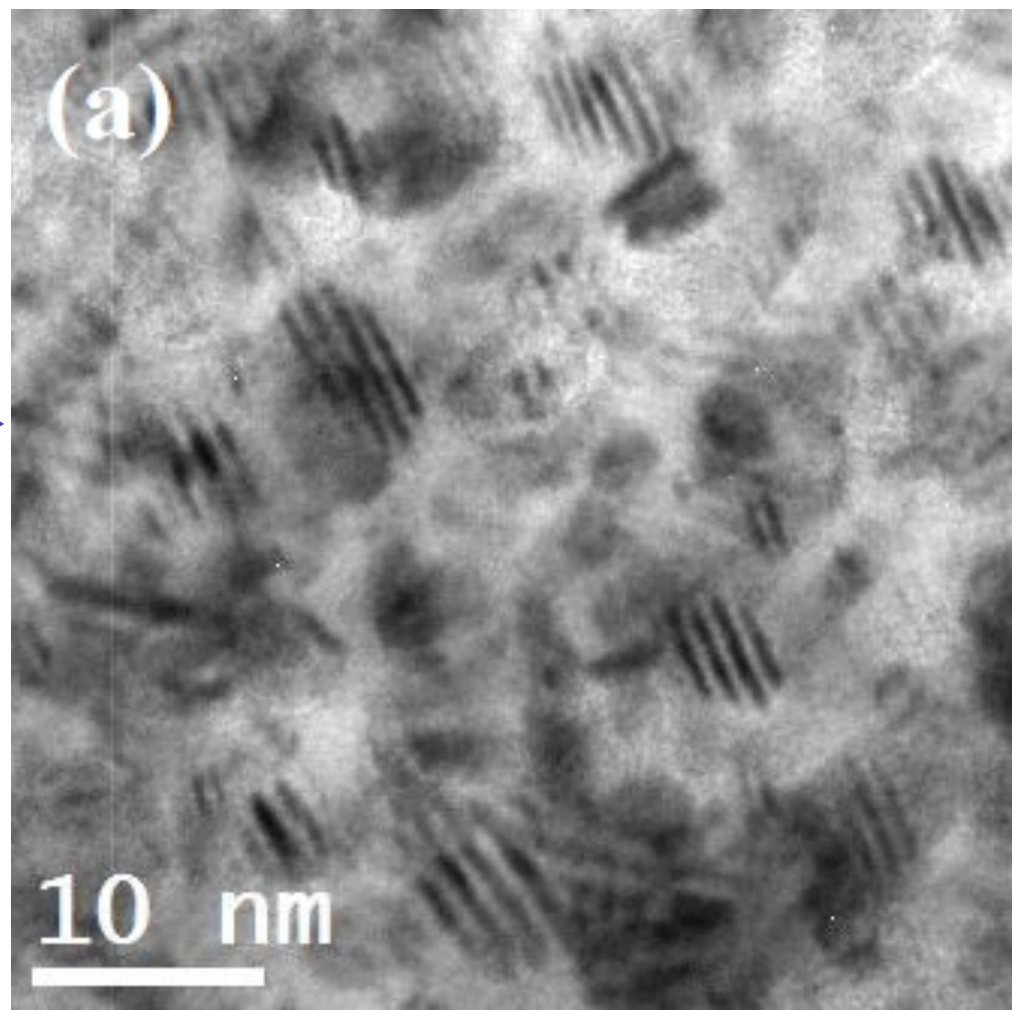

BF-TEM 


\section{B. Nanostructuring in $\mathrm{Cu}-\mathrm{Nb}-\mathrm{W}$ thin films: Precipitation in samples first irradiated at RT (3)}

- Experimental results, cont'd:

- Log-normal distribution

- Precipitate structure: ramified core/ filling shell

- Coarsening resistant: no change from 1 to $10 \mathrm{hr}$ anneal

(b)

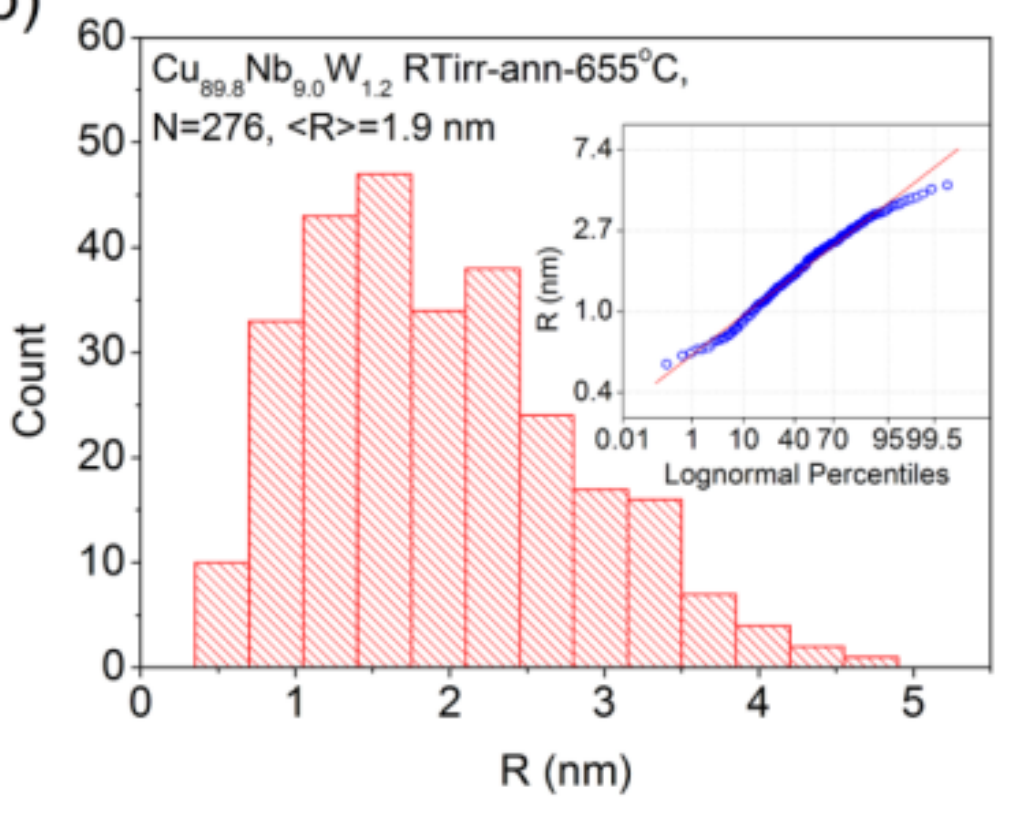

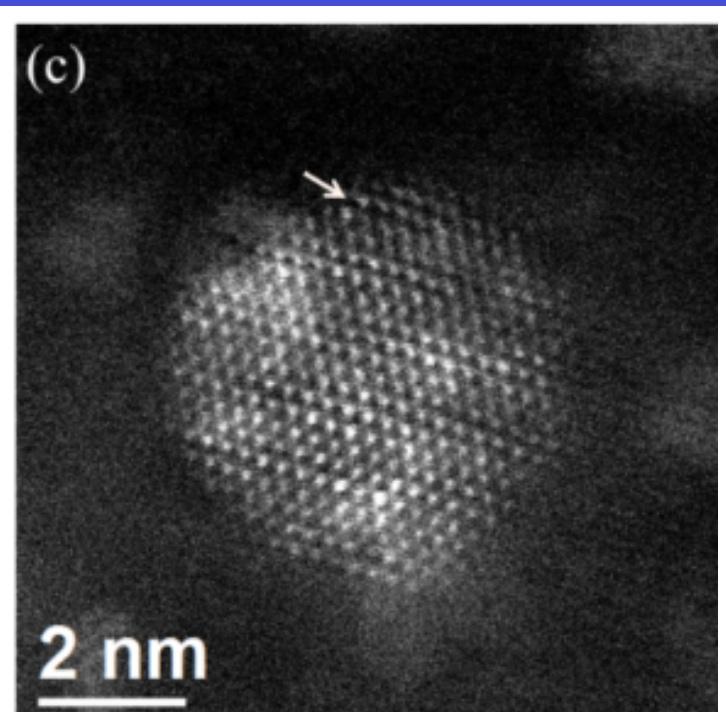

(c)

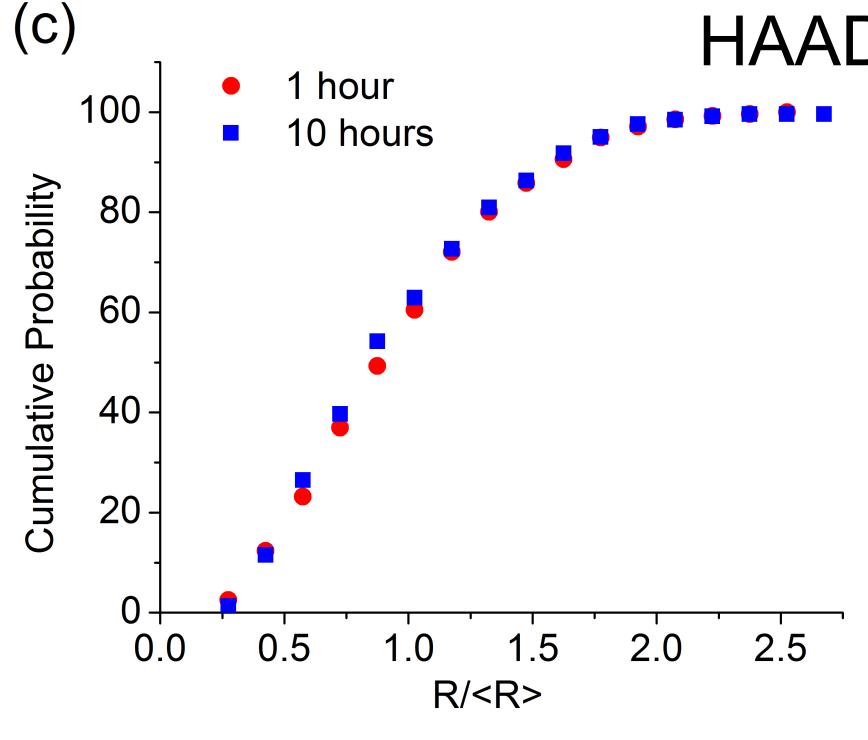




\section{Nanostructuring in $\mathrm{Cu}-\mathrm{Nb}-\mathrm{W}$ thin films: Modeling by atomistic kinetic Monte Carlo}

- Set-up: $A_{89} B_{10} C_{1}$ ternary system; rigid $F C C$ lattice; single vacancy; pairwise interactions, first n-n; residence time algorithm (Monte Carlo)

- Generic study to look at the effect of competition between kinetics and driving force for precipitation that exists in the experimental system.

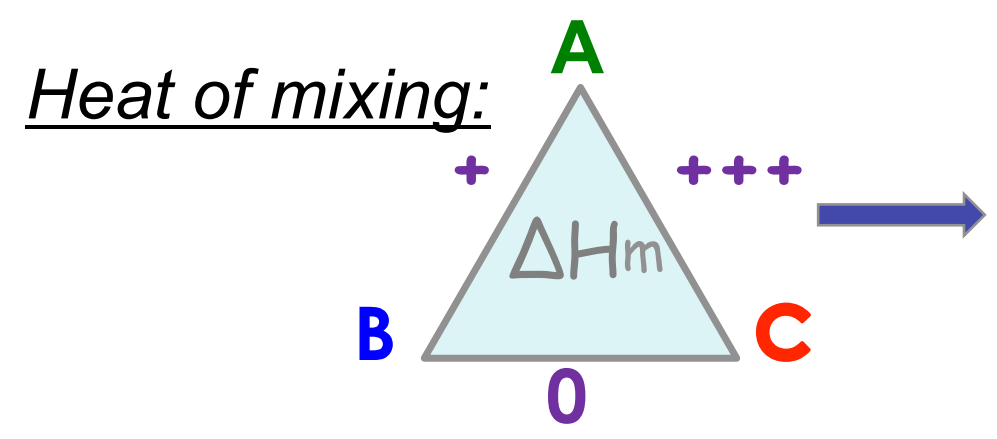

\section{The driving force for precipitation} is larger for $C$ than for $B$.

Vacancy migration energy in pure $A, B$ or $C$ elements:

$E_{V, \text { mig }}^{A}=E_{V, \text { mig }}^{B}$

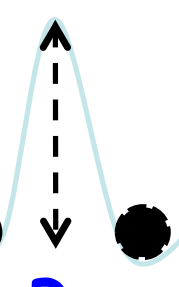

A, B

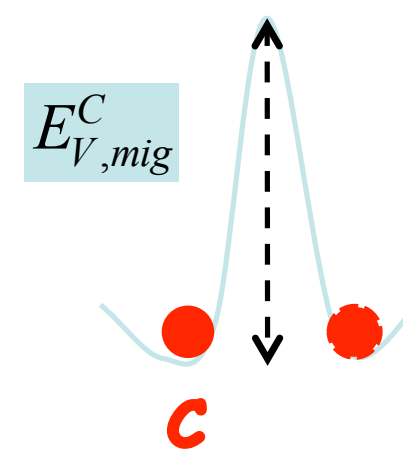

$c$
The kinetics is much slower for $\mathrm{C}$ than for $\mathrm{B}$. 


\section{Modeling by atomistic kinetic Monte Carlo: Direct annealing at high temperature}
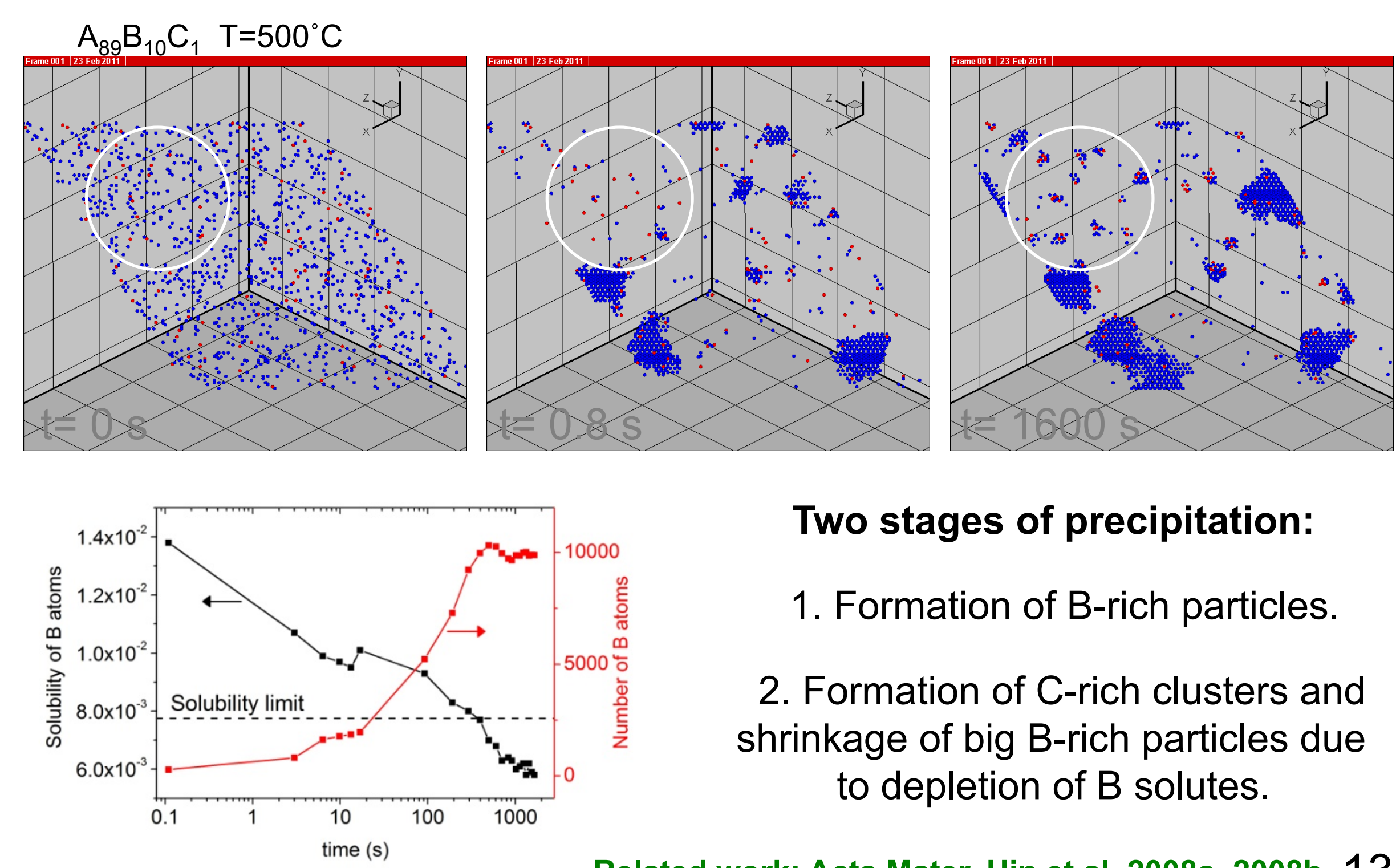

\section{Two stages of precipitation:}

1. Formation of B-rich particles.

2. Formation of C-rich clusters and shrinkage of big B-rich particles due to depletion of B solutes.

Related work: Acta Mater. Hin et al. 2008a, 2008b 13 


\section{Modeling by atomistic kinetic Monte Carlo: HT annealing of samples with pre-existing C-precipitates}

- Construct the initial structures with two types of W clusters: spherical and ramified (fractal).

- Anneal at $\mathrm{T}=500^{\circ} \mathrm{C}$.

- Ramified core/compact shell

- Lognormal distribution

- Coarsening stalls
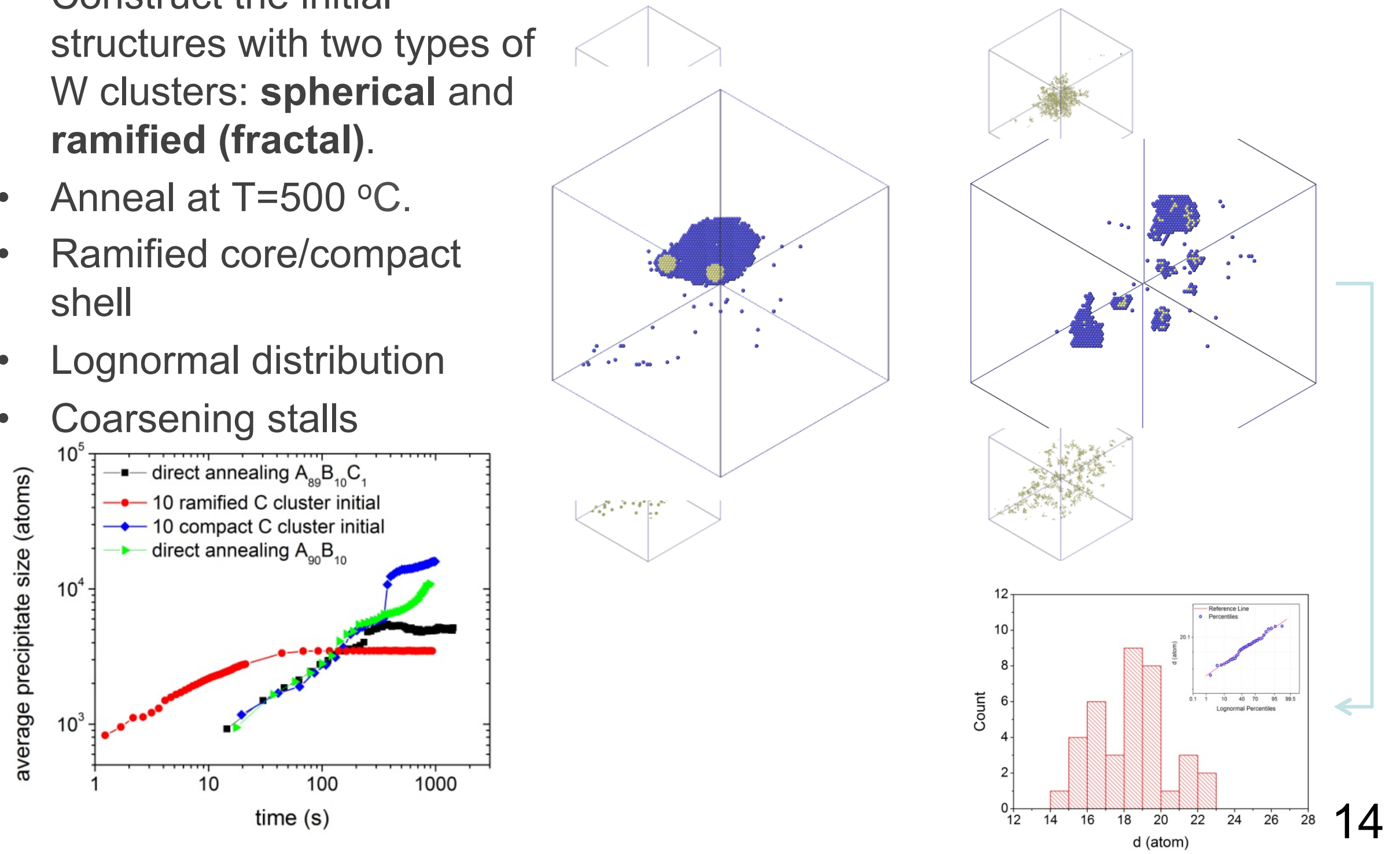
Part II: High radiation resistance provided by interfaces: the case of $\mathrm{Cu}-\mathrm{Nb}$
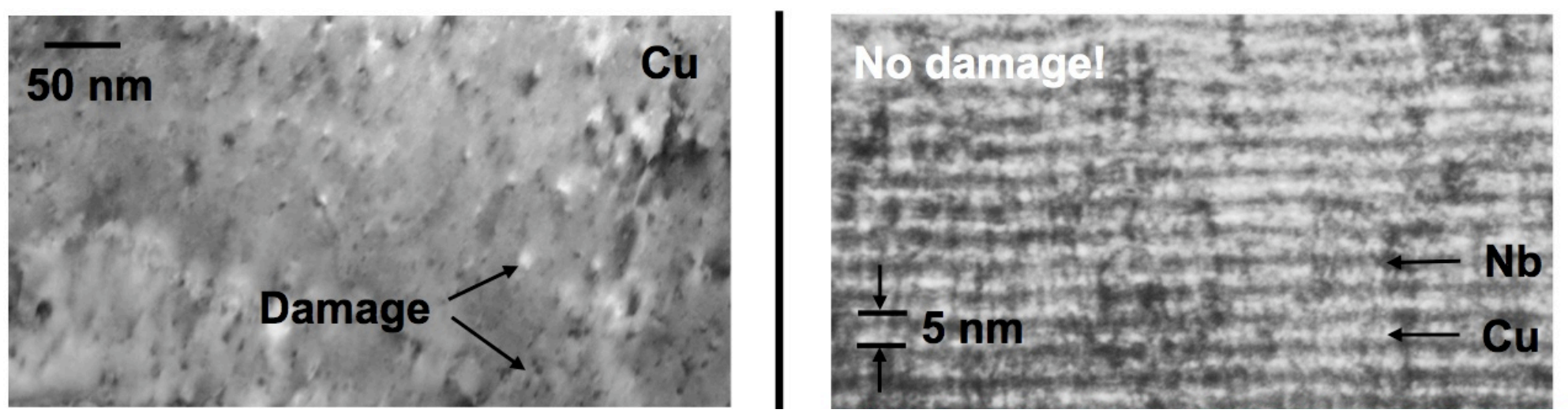

A. Misra et al. JOM 2007, 2010
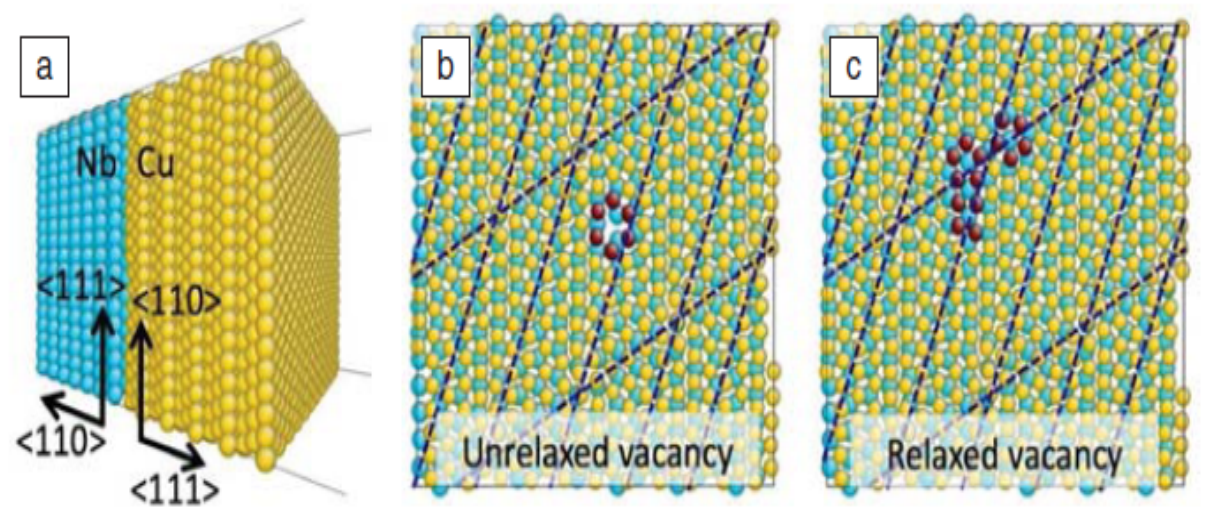

M.J. Demkowicz et al. PRL 2008

- How to evaluate sink efficiency?

$\rightarrow$ Other groups: Bubble formation after $\mathrm{He}, \mathrm{Kr}$ implantation and irradiation 


\section{Quantitative evaluation of sink efficiency at interfaces by marker diffusion}

Broadening of marker layer

Model sample Irradiated sample

$5 \mathrm{~nm}$

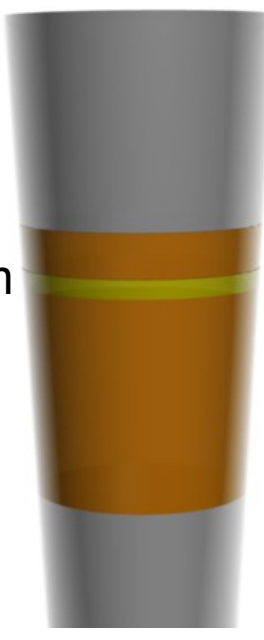

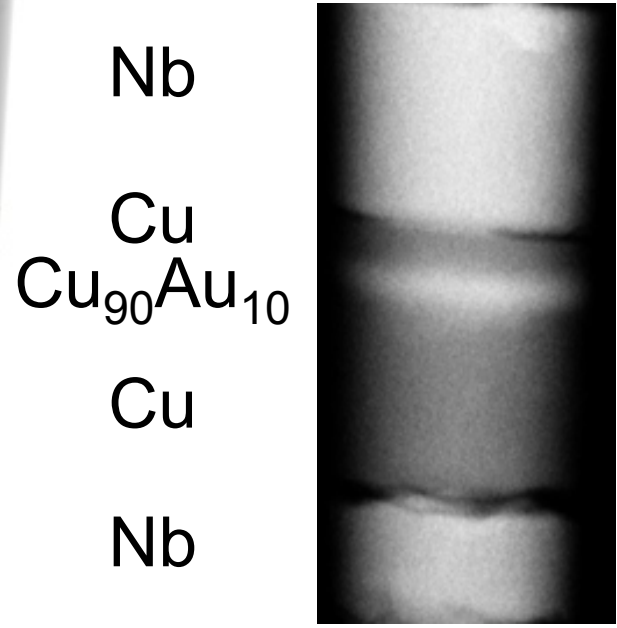

HAADF-TEM
STEM-EDS chemical analysis

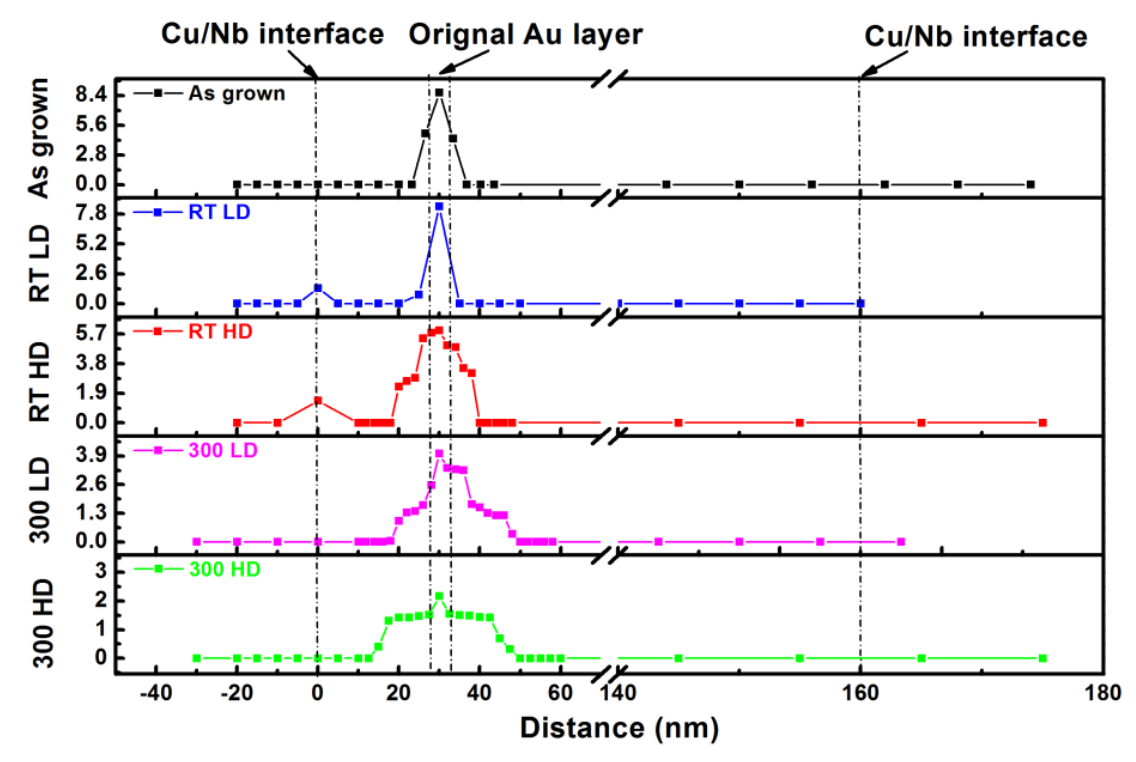

- Makes it possible to evaluate sink efficiency as a function of interface properties (misfit dislocations)

- Compare $\{111\} K S$ (PVD) with $\{112\} K S$ (ARB)

- Compare Cu-V with Cu-Nb 


\section{Comparison of vacancy profile with rate-theory calculations}

(Sizmann, J. Nucl. Mater. 1978)

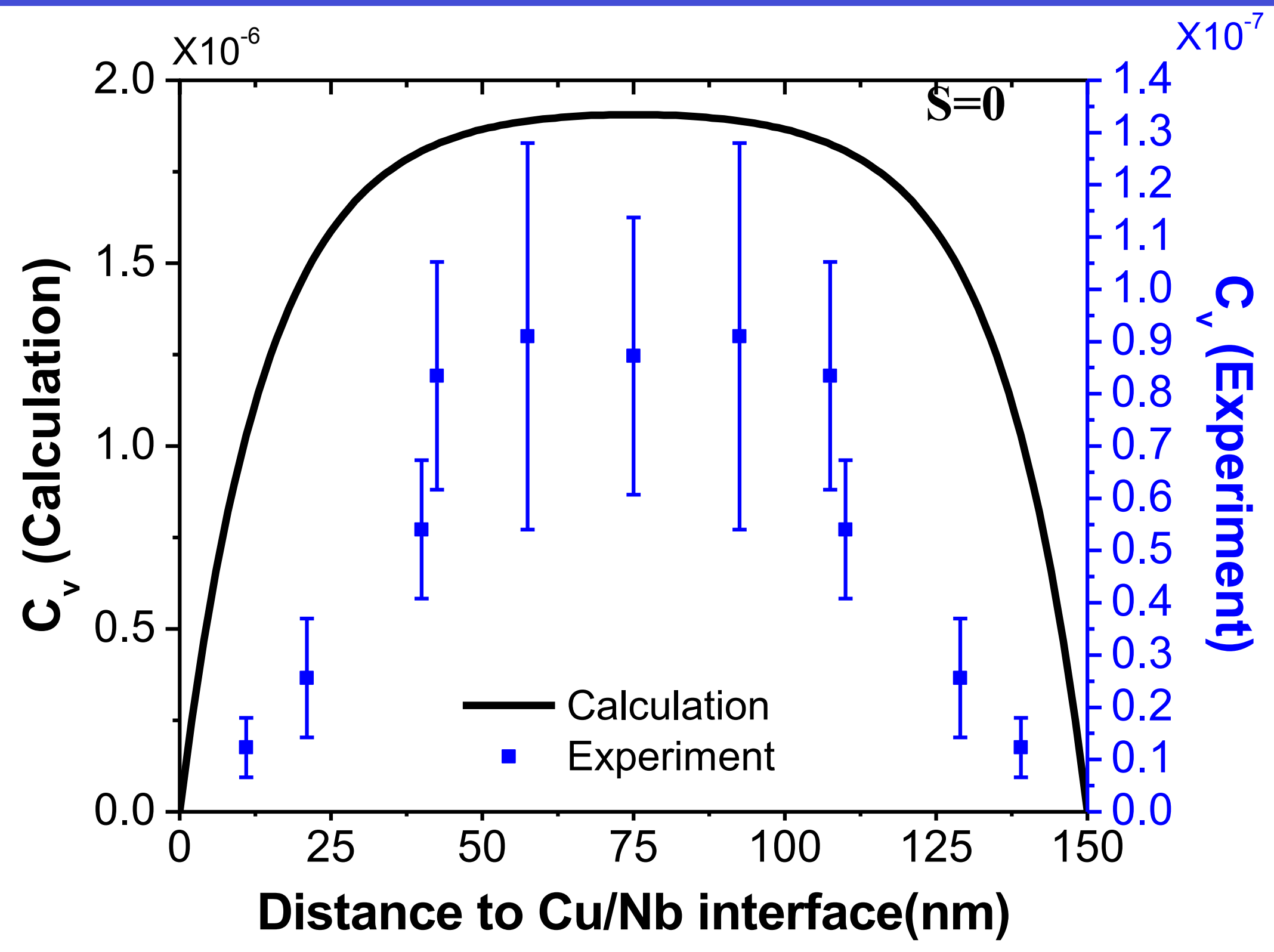




\section{Conclusions}

$\rightarrow$ Tailoring nanostructured materials for improved radiation resistance

$\rightarrow$ Pre-RT irradiation in suitable alloy systems can completely suppress coarsening;

Severe plastic deformation may be used alternative to RT irradiation

$\rightarrow$ Design of experiments to quantitatively evaluate sink efficiency 